\title{
Atuação do enfermeiro para prevenção de infecções pela SARS- CoV2 no centro cirúrgico durante a pandemia da COVID-19
}

The nurse's role in preventing SARS-CoV2 infections in the operating room during the COVID-19 pandemic

El papel de la enfermera en la prevención de infecciones por SARS-CoV2 en el quirófano durante la pandemia de COVID-19

Recebido: 10/06/2021 | Revisado: 18/06/2021 | Aceito: 01/07/2021 | Publicado: 17/07/2021

Jorgeany Soares Parente

ORCID: https://orcid.org/0000-0002-0457-9481 Universidade do Estado do Pará, Brasil E-mail: jorgeanysoares@famaz.edu.br

Adriane Stefhani Cardoso Fonseca ORCID: https://orcid.org/0000-0002-6134-1728 Centro Universitário Metropolitano da Amazônia, Brasil E-mail: adrianestefhani03@gmail.com

Ana Carolina Marinho Pinheiro

ORCID: https://orcid.org/0000-0002-3762-4621 Centro Universitário Metropolitano da Amazônia, Brasil E-mail: karolinamarinho@hotmail.com

Esther Miranda Caldas

ORCID: https://orcid.org/0000-0002-0457-7216 Centro Universitário Metropolitano da Amazônia, Brasil E-mail:esthermicaldas24@gmail.com Jucilene Luz Neves

ORCID: https://orcid.org/0000-0002-4175-9174 Centro Universitário Metropolitano da Amazônia, Brasil E-mail: juhneves60@gmail.com

Maria Paula dos Santos Sousa Bulhões Costa ORCID: https://orcid.org/0000-0003-0967-352X Centro Universitário Metropolitano da Amazônia, Brasil E-mail: mariapaula@linknet.com.br

Rogéria de Sousa Rodrigues

ORCID: https://orcid.org/0000 000162012259 Centro Universitário Metropolitano da Amazônia, Brasil E-mail: rogeriasousa440@yahoo.com.br

Thaís Neves de Souza

ORCID: https://orcid.org/0000-0001-6335-6918 Centro Universitário Metropolitano da Amazônia, Brasil E-mail: thaisnds8@gmail.com

\begin{abstract}
Resumo
Objetivo: O presente estudo tem como objetivo descrever a partir da análise e revisão da literatura a atuação dos profissionais de saúde para prevenção de infecções pelo SARS- CoV2 no centro cirúrgico durante a pandemia da COVID-19. Metodologia: Trata-se de uma revisão integrativa de literatura, descritiva baseadas em estudos publicados nos períodos de 2016 a 2021. A revisão integrativa é um estudo que determina o conhecimento sobre a temática específica, este estudo é conduzido para a identificar, analisar e sintetizar resultados de estudos independentes a respeito do assunto, contribuindo para a qualidade no âmbito da pesquisa. Resultados: Por meio da Classificação Hierárquica Descendente (CHD) o software IRAMUTEQ reconheceu nesta pesquisa 138 segmentos de textos (ST) e manteve 98 destes seguimentos, obtendo o total de 71,01\% de aproveitamento. A partir disso, sucedeu a divisão do corpus em 6 classes, na qual a classe 1 corresponde a $16,3 \%$ de palavras no corpus, a classe 2 corresponde a $18,4 \%$, a classe 3 corresponde a 14,3\%, a classe 4 corresponde a 21,4\%, a classe 5 corresponde a 14,3\% e a classe 6 corresponde a 15,3\%. Considerações finais: É indiscutível o papel da enfermagem dentro desse contexto, pois é uma das profissões em que há maior convívio junto aos pacientes e nesse sentido é importante que esta realize medidas específicas para a prevenção da disseminação de microrganismos no ambiente hospitalar, sobretudo no centro cirúrgico em vigência da pandemia da COVID-19.
\end{abstract}

Palavras-chave: Centro cirúrgico; Controle de infecções; Coronavírus; EPI; Profissionais de saúde. 


\begin{abstract}
Objective: The present study aims to describe, from the analysis and review of the literature, the role of health professionals in preventing infections by SARS-CoV2 in the operating room during the COVID-19 pandemic. Methodology: This is an integrative literature review, descriptive based on studies published in the periods from 2016 to 2021. The integrative review is a study that determines knowledge about the specific theme, this study is conducted to identify, analyze and synthesize results of independent studies on the subject, contributing to quality in the scope of the research. Results: Through the Descending Hierarchical Classification (CHD) the IRAMUTEQ software recognized 138 text segments (ST) in this research and maintained 98 of these segments, obtaining a total of $71.01 \%$ of utilization. Thereafter, the corpus was divided into 6 classes, in which class 1 corresponds to $16.3 \%$ of words in the corpus, class 2 corresponds to $18.4 \%$, class 3 corresponds to $14.3 \%$, class 4 corresponds to $21.4 \%$, class 5 corresponds to $14.3 \%$ and class 6 corresponds to $15.3 \%$. Final considerations: The role of nursing in this context is indisputable, as it is one of the professions in which there is greater contact with patients and, in this sense, it is important that they carry out specific measures to prevent the spread of microorganisms in the hospital environment, especially in the center during the COVID-19 pandemic.
\end{abstract}

Keywords: Surgical center; Infection control; Coronavirus; PPE; Health professionals.

\title{
Resumen
}

Objetivo: El presente estudio tiene como objetivo describir, a partir del análisis y revisión de la literatura, el papel de las profesionales de la salud en la prevención de infecciones por SARS-CoV2 en el quirófano durante la pandemia de COVID-19. Metodología: Se trata de una revisión de literatura integradora, descriptiva basada en estudios publicados en los períodos de 2016 a 2021. La revisión integrativa es un estudio que determina el conocimiento sobre el tema específico, este estudio se realiza para identificar, analizar y sintetizar resultados de estudios independientes sobre el tema, contribuyendo a la calidad en el ámbito de la investigación. Resultados: A través de la Clasificación Jerárquica Descendente (CHD), el software IRAMUTEQ reconoció 138 segmentos de texto (ST) en esta investigación y mantuvo 98 de estos segmentos, obteniendo un total de $71.01 \%$ de utilización. A partir de entonces, el corpus se dividió en 6 clases, en las que la clase 1 corresponde al 16,3\% de las palabras del corpus, la clase 2 corresponde al 18,4\%, la clase 3 corresponde al 14,3\%, la clase 4 corresponde al $21,4 \%$, la clase 5 corresponde al 14,3\% \% y la clase 6 corresponde al $15,3 \%$. Consideraciones finales: El papel de la enfermería en este contexto es indiscutible, ya que es una de las profesiones en las que hay mayor contacto con los pacientes y, en este sentido, es importante que realicen medidas específicas para prevenir la propagación de microorganismos en el ambiente hospitalario, especialmente en el centro durante la pandemia de COVID-19.

Palabras clave: Centro quirúrgico; Control de infecciones; Coronavirus; EPI; Profesionales de la salud.

\section{Introdução}

Mundialmente o início de 2020 ficou marcado por um surto de pneumonia causada por um tipo de coronavírus, tendo seu primeiro caso registrado em dezembro de 2019 na cidade de Wuhan, na China. Tomando uma rápida proporção com um número elevado de caso alterando de imediato o perfil epidemiológico de infecção para surto, sendo declarada no Brasil no final de janeiro de 2020 pela Organização Mundial de Saúde (OMS) como condição de emergência em saúde pública mundial (Oliveira; Lucas; Iquiapaza, 2020).

Os coronavírus são um grupo de vírus de RNA com sentido positivo, envelopados com estratégia de replicação única possibilitando que varie a sua patogenicidade e facilitando a sua adaptação em ambientes variados. O SARS-CoV-2 provém de uma nova cepa identificada em 2019 é o novo agente do coronavírus e até agora não foi isolada em humanos, as ações planejadas para enfrentar a pandemia objetivam a destruição do vírus evitando a sua transmissão. O SARS-CoV-2 causa a doença COVID19, uma sigla que vem do inglês Coronavírus, e é responsável por milhões de mortes em todo o mundo (Brasil, 2020).

Diante de uma pandemia e a partir do primeiro caso notificado no país pela OMS causado pelo novo coronavírus, medidas administrativas foram tomadas para que o país entrasse em alerta e se preparasse para enfrentar a pandemia, ações como a higienização das mãos e etiqueta respiratória foram fortalecidas (Oliveira; Lucas; Iquiapaza, 2020). Há um desafio mundial dos sistemas de saúde para retomar a normalidade dos serviços mantendo uma assistência adequada para o paciente e preservando a sua segurança diante da situação atual, formulando medidas voltadas tanto a proteção do paciente quanto dos profissionais que atuam diretamente no ambiente hospitalar, por meio da adesão rigorosa aos protocolos institucionais (Takeiti; Oliveira; Cruz, 2021). 
Quando a OMS declarou a pandemia do novo coronavírus, as cirurgias eletivas foram suspensas por um determinado período, como recomendações das entidades governamentais, sendo realizadas apenas cirurgias de urgência e emergência, por volta de abril de 2020 devido ao aumento do número de casos de pacientes precisarem de cirurgias, houve o início da retomada gradual das cirurgias eletivas, mas com novos protocolos de segurança, juntamente a volta houve o desafio, para que esses pacientes entrassem e saíssem da instituição sem contrair o vírus, para isso foi demandada as seguintes normas e restrições: leitos exclusivos, PCR SARS-CoV2 de 48 a 72 horas antes do procedimento cirúrgico, elevadores exclusivos, uso de máscara n95 para toda equipe de cirurgia e máscara cirúrgica para os pacientes, aplicação dos termos de consentimento exclusivos, entre outros (Takeiti; Oliveira; Cruz, 2021).

A repercussão na prestação de cuidados foi evidente e suas rotinas e procedimentos foram alterados devido aos riscos a que os profissionais de saúde estavam expostos, tornando-se necessário estar sempre alerta e adotando medidas de segurança para contenção do vírus no ambiente hospitalar, sendo necessário desde a entrada no hospital, a retirada de adornos, a troca dos calçados, a higienização das mãos e o banho ao final do plantão, a fim de evitar possível contaminação e otimizar os cuidados intensivos ao paciente com COVID-19 (Busanello et al., 2019).

A respeito das medidas de prevenção em diversos aspectos, assim como, as medidas de controle que devem ser realizadas da entrada até a saída dos pacientes das instituições de saúde, sejam estes suspeitos ou confirmados, tanto profissionais de saúde quanto a equipe de gestão das instituições podem adotar medidas de controle mais restritas, porém deve-se basear em documentos atualizados. Portanto esses protocolos institucionais, estão voltados em suma, ao uso de EPIS pelos membros das instituições e profissionais de saúde. Dessa maneira, todos os profissionais que realizem atividades com menos de um metro de distância dos pacientes devem seguir os seguintes passos como: higienização das mãos, utilizar óculos ou protetor facial, máscara N95, caso faça procedimentos que gerem aerossóis, luvas, gorro e avental impermeável (Junior et al., 2020).

O centro cirúrgico é considerado o local onde mais ocorrem eventos adversos, logo para que os procedimentos cirúrgicos sejam seguros é imprescindível a tomada de medidas durante o período perioperatório, para que haja redução de eventos adversos que possam causar danos a vida dos pacientes (Mendes; Araújo; Morgan, 2020). A estrutura física do centro cirúrgico é composta de: sala de recuperação pós-anestésica (RPA), centro de material e esterilização (CME) e centro cirúrgico (CC). Portanto são locais onde pacientes serão submetidos a procedimentos anestésico-cirúrgicos, conforme os protocolos de segurança exigem, objetiva fornecer conforto e segurança para equipe multiprofissional e paciente (Silva; Brasileiro, 2018).

No que tange a segurança dos blocos cirúrgicos novas medidas foram tomadas a fim de evitar a propagação do novo coronavírus, entre elas está a biossegurança da equipe e do paciente no ambiente cirúrgico, redução da quantidade de profissionais para atuar durante os procedimentos, esterilização tanto do bloco cirúrgico como dos materiais utilizados, além da introdução da cirurgia robótica como auxílio durante os procedimentos viabilizando a diminuição dos dias de internação. Ao final de cada procedimento a equipe de limpeza deve aguardar 30 minutos para poder entrar e realizar a desinfecção do bloco cirúrgico preparando para a próxima cirurgia, proporcionando menor risco de contaminação no ambiente (Gemir et al., 2020).

A pandemia da COVID-19 trouxe vários desafios para o sistema de saúde muitas incertezas e constante medo em face do desconhecido, obrigando a todos a realizar ações básicas de cuidado para o controle e prevenção da infecção. Dentre essas ações estratégicas destacasse o reforço da higienização correta das mãos e o uso de solução antisséptica de base alcoólica (SABA), paramentação e desparamentação correta dos equipamentos de proteção individual (EPIs), isolamento dos pacientes contaminados, criação de novos protocolos de segurança hospitalar a fim de evitar a propagação da contaminação causada pelo novo coronavírus (SARS- CoV2) (Parreira et al., 2020).

Os cuidados de enfermagem aliado a equipe multiprofissional nunca foi tão efetivo e importante, o engajamento da equipe, a sistematização do cuidado juntamente com o apoio de gestores e das instituições que permitiu que fosse possível preparar a equipe e o ambiente hospitalar para que as adaptações nas estruturas contribuíssem para a prestação dos cuidados de 
enfermagem, uma vez que se passou a exigir intervenções mais específicas por conta da infecção. Por ser atuante na maioria dos cuidados o profissional de enfermagem continua intervindo de modo holístico e sensível uma vez que se tornara a única companhia do paciente quando este se encontrava isolado e sem receber visita durante o período de internação hospitalar (Parreira et al., 2020).

O presente estudo tem como objetivo descrever a partir da análise e revisão da literatura a atuação dos profissionais de saúde na prevenção de infecções pelo SARS- CoV2 no centro cirúrgico durante a pandemia da COVID-19.

\section{Métodos}

Trata-se de uma revisão integrativa de literatura, descritiva baseadas em estudos publicados nos períodos de 2016 a 2021. A revisão integrativa é um estudo que determina o conhecimento sobre a temática específica, este estudo é conduzido para a identificar, analisar e sintetizar resultados de estudos independentes a respeito do assunto, contribuindo para a qualidade no âmbito da pesquisa (Souza, et al., 2010). As etapas metodológicas realizadas foram: definição do tema, elaboração da questão norteadora, formulação dos critérios de inclusão e exclusão, definição dos descritores, coleta de dados, análise dos artigos selecionados e discussão dos resultados obtidos.

Portanto, o estudo sustentou-se a partir da seguinte questão norteadora: Qual atuação do enfermeiro para prevenção de infecções pela SARS- CoV2 no centro cirúrgico durante a pandemia da COVID-19?

O levantamento dos artigos foi realizado entre os meses de março e abril de 2021, por meio das bases de dados: Base de Dados de Enfermagem (BDENF); Literatura Latino-Americana e do Caribe em Ciencias da Saúde (LILACS) e Scientific Eletronic Library Online (SciELO). Utilizando-se dos descritores validados no Descritores em Ciências da Saúde (DeCS): Centro cirúrgico; controle de infecções; coronavírus; EPI e profissionais de saúde. Os descritores foram cruzados através do operador booleano "AND" para filtrar a busca dos assuntos.

Foram considerados como critérios de inclusão: artigos em português, com texto completo que abordasse a respeito da temática. Os critérios de exclusão definidos foram: artigos em inglês e espanhol, artigos repetidos, incompletos e que não contemplassem temática relevante ao objetivo do estudo. Após estabelecer os critérios de inclusão ou exclusão, foram realizadas as pesquisas na base de dados, seguindo fases para seleção, sendo a primeira a leitura do título e resumo dos artigos para constatar quais artigos se adequavam aos critérios de inclusão e exclusão estabelecidos. Após a leitura do título e resumo, na segunda fase era realizada a leitura completa do artigo. Na primeira foram excluídos artigos que não estavam relacionados ao objetivo do trabalho, e, na segunda fase foi realizada a leitura completa dos artigos para avaliar a inclusão levando em consideração seu s resultados, discussões e conclusões.

Inicialmente, foram identificados, 32.851 publicações, entretanto, após a aplicação dos critérios de exclusão, a quantidade de publicações reduziu para 1.425 artigos. Sendo 1.250 na base LILACS, 145 na BDENF e 30 na SCIELO. Portanto, para a seleção dos artigos realizou-se a leitura dos títulos e resumos, selecionou-se 33 estudos para a leitura na integra e excluíram-se 1.392 artigos por não estarem completos ou não responderem à questão da pesquisa. Após a leitura na integra foram selecionadas 14 publicações para compor a amostra do estudo, Além dos artigos selecionados nas bases de dados, foram utilizadas também duas Normas Técnicas da Anvisa. Representa-se, na figura 1, o fluxograma do processo de seleção dos artigos. 
Figura 1: Fluxograma da metodologia de seleção dos artigos.
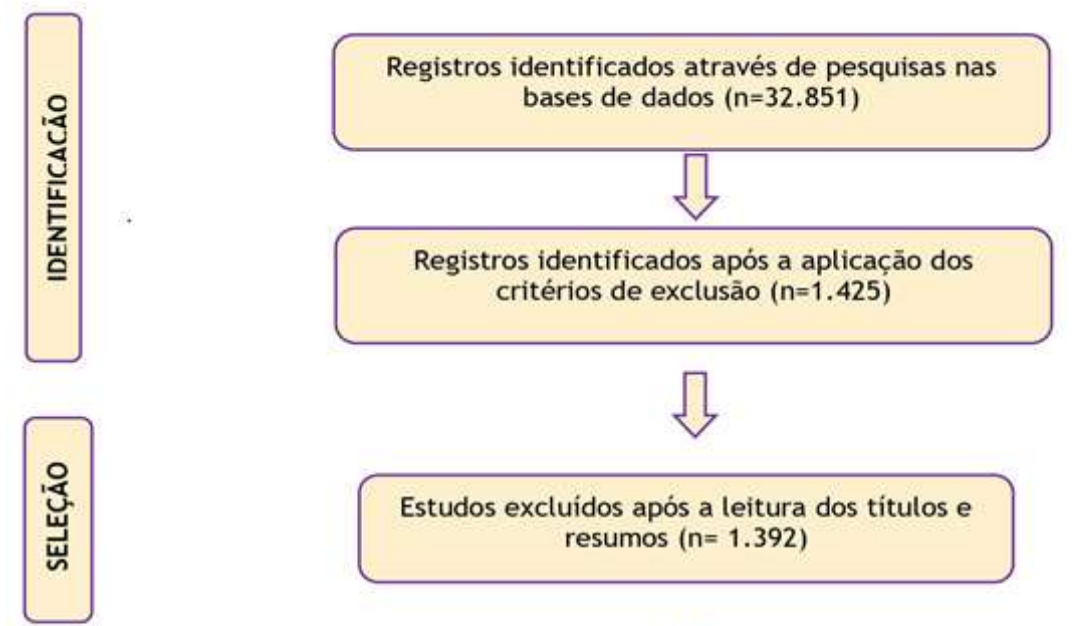

Estudos excluidos após a leitura dos títulos e resumos $(n=1.392)$
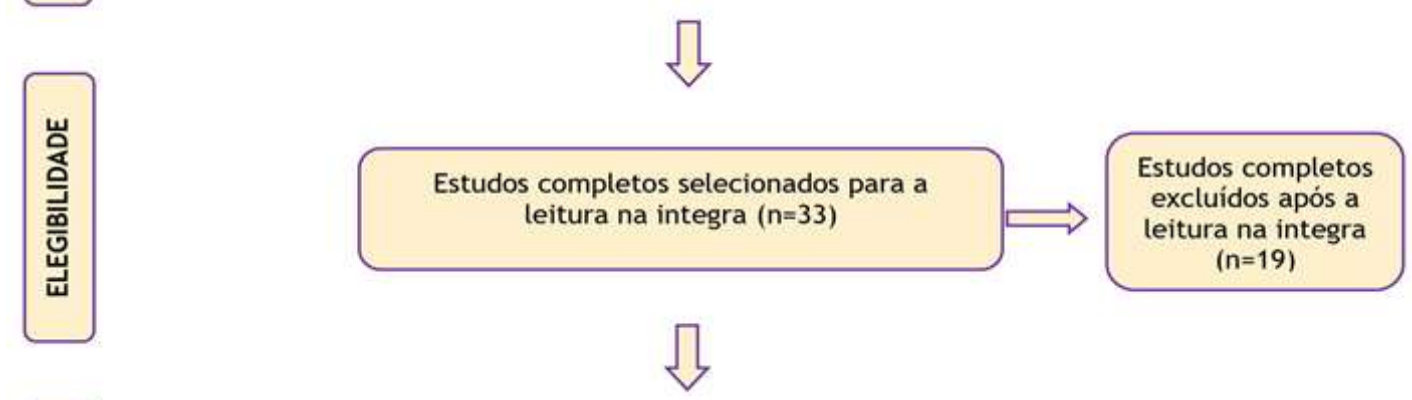

일

Estudos incluidos após leitura completa $(n=14)$

Fonte: Autores (2021).

Após a inclusão dos artigos para a amostra, foi elaborado o corpus de cada para a utilização do IRAMUTEQ. O IRAMUTEQ (Interface de R pour les Analyses Multidimensionnelles de Textes et de Questionnaires), é um software criado por Pierre Ratinaud. Este softwares começou a ser utilizado no Brasil em 2013 em pesquisa e contribui para a identificação de várias possibilidades de processamento de dados qualitativos, tendo em vista que este permite diferentes formas de análises estatísticas de textos. (Souza, et al,. 2018).

Para o presente estudo, foi utilizada a Classificação Hierárquica Descendente (CHD), que é uma das espécies de análises realizadas pela ferramenta software IRAMUTEQ. Além desta, o IRAMUTEQ incluiu outras formas de análises, como as textuais de forma clássica, similitude e nuvem de palavras. (Souza, et al,. 2018). Durante o processamento do corpus, o IRAMUTEQ® reconheceu a separação do corpus em 14 conjuntos de textos com 138 seguimentos de textos. Teve como aproveitamento de 98 seguimentos de texto, ou seja, $71,01 \%$ do corpus foi aproveitado para análise. Após a obtenção dos resultados do IRAMUTEQ® foi elaborada as classes com as palavras que apresentaram maior frequência para a realização da discussão do presente estudo.

\section{Resultados}

Os artigos selecionados foram lidos na integra e meticulosamente analisados para fazer parte dos dados de amostra da pesquisa, condizente ao que será apresentado a seguir (Quadro 1). Depois de analisar criticamente os estudos e identificar 14 
produções, os estudos foram agregados por meio do instrumento de URSI (2006). Na qual optamos por selecionar os seguintes itens: Autor/Ano; Periódicos; Título; Objetivos do estudo; Resultados.

Quadro 1 - Artigos que foram utilizados como amostra selecionados nas bases BDENF, LILACS e SCIELO entre os anos de 2016 a 2021.

\begin{tabular}{|c|c|c|c|c|}
\hline $\begin{array}{l}\text { Autor/ } \\
\text { Ano: }\end{array}$ & Periódico: & Título & Objetivos do estudo & Resultado \\
\hline $\begin{array}{l}\text { Trevilato, D. D., } \\
\text { Jost, M. T., } \\
\text { Araujo, B. R., } \\
\text { Martins, F. Z., } \\
\text { Maga lhães, A. } \\
\text { M. M. D., \& } \\
\text { Caregnato, R. C. } \\
\text { A. (2020). }\end{array}$ & $\begin{array}{l}\text { Rev. } \\
\text { SOBECC, } \\
187-193 .\end{array}$ & $\begin{array}{lr}\text { Centro cirúrgico: } \\
\text { recomendações para } \\
\text { o atendimento de } \\
\text { pacientes } \quad \text { com } \\
\text { suspeita } & \text { ou } \\
\text { portadores } & \text { de } \\
\text { COVID-19. } & \end{array}$ & $\begin{array}{lr}\text { Apresentar } & \text { as } \\
\text { recomendações para } \\
\text { reorganização do centro } \\
\text { cirúrgico no atendimento a } \\
\text { pacientes com suspeita ou } \\
\text { confirmação de COVID- } \\
19 .\end{array}$ & $\begin{array}{l}\text { A gestão dos recursos humanos e materiais é } \\
\text { primordial para: atender à demanda assistencial } \\
\text { perioperatória; reorganizar os procedimentos } \\
\text { cirúrgicos; garantir a segurança dos } \\
\text { profissionais de saúde; organizar a sala cirúrgica } \\
\text { com materiais necessários; planejar a } \\
\text { recuperação pós-anestésica do paciente; e } \\
\text { realizar limpeza e desinfecção da sala cirúrgica. }\end{array}$ \\
\hline $\begin{array}{l}\text { Jesus, M. R. C. } \\
\text { D., Melo, M. G., } \\
\text { Campos, M. P. } \\
\text { D. A., Barbosa, } \\
\text { T. O., Abud, A. } \\
\text { C. F., \& } \\
\text { Lordelo, D. D. } \\
\text { S. }(2020) \text {. }\end{array}$ & $\begin{array}{l}\text { Rev. } \\
\text { SOBECC, 91- } \\
98 .\end{array}$ & $\begin{array}{l}\text { Avaliação da } \\
\text { adequação no uso da } \\
\text { paramentação } \\
\text { cirúrgica. }\end{array}$ & $\begin{array}{l}\text { Analisar a adequação da } \\
\text { paramentação cirúrgica } \\
\text { pelos profissionais de } \\
\text { saúde que prestam } \\
\text { assistência em um centro } \\
\text { cirúrgico de um hospital } \\
\text { de ensino no Nordeste do } \\
\text { Brasil. }\end{array}$ & $\begin{array}{l}\text { Os itens de maior adequação foram: no } \\
\text { momento da colocação do propé e das luvas } \\
(100 \%) \text {, seguido da circulação da roupa } \\
\text { privativa e do momento de colocação do gorro } \\
(99 \%) \text {. Obtiveram-se menores taxas de } \\
\text { adequação no uso dos óculos }(5 \%) \text { e quanto ao } \\
\text { local de guarda da máscara (8\%). As } \\
\text { inadequações relacionadas à máscara cirúrgica } \\
\text { ocorreram pela não troca mediante sujidade ou } \\
\text { umidade e em cirurgias com duração maior de } \\
\text { duas horas aproximadamente (23\%). }\end{array}$ \\
\hline $\begin{array}{l}\text { Correia, M. I. T. } \\
\text { D., Ramos, R. } \\
\text { F., \& Bahten, L. } \\
\text { C. V. (2020). }\end{array}$ & $\begin{array}{l}\text { Revista do } \\
\text { Colégio } \\
\text { Brasileiro de } \\
\text { Cirurgiões, } \\
47 .\end{array}$ & $\begin{array}{l}\text { Os cirurgiões e a } \\
\text { pandemia } \\
\text { COVID-19. }\end{array}$ & $\begin{array}{l}\text { Sensibilizar as instituições } \\
\text { científicas para assumir a } \\
\text { liderança no } \\
\text { esclarecimento de fatos e } \\
\text { verdades, a respeito da } \\
\text { pandemia da covid } 19 .\end{array}$ & $\begin{array}{l}\text { O Colégio Brasileiro de Cirurgiões tem ciência } \\
\text { da amplitude das informações e que suas } \\
\text { evidências científicas ainda são instáveis, } \\
\text { portanto, sugere medidas que promovam a } \\
\text { qualidade e segurança aos pacientes e } \\
\text { profissionais de saúde. Utilizando seu veículo } \\
\text { científico, a Revista do Colégio Brasileiro de } \\
\text { Cirurgiões, que propõe medidas de qualidade e } \\
\text { segurança que visam orientar os profissionais } \\
\text { cirurgióes e os pacientes, se baseando nas } \\
\text { informações disponíveis na literatura científica } \\
\text { até o momento e nas diretrizes e estratégias do } \\
\text { Ministério da Saúde do Brasil. }\end{array}$ \\
\hline $\begin{array}{l}\text { Cunha, A. G., } \\
\text { Peixoto, T. L., } \\
\text { Gomes, L. C. P., } \\
\text { Bastos, V. D. S., } \\
\text { Cavalcanti, T. } \\
\text { P., \& Gusmão- } \\
\text { Cunha, A. M. } \\
(2020) .\end{array}$ & $\begin{array}{l}\text { Revista do } \\
\text { Colégio } \\
\text { Brasileiro de } \\
\text { Cirurgiões, } \\
47 .\end{array}$ & $\begin{array}{l}\text { Como preparar o } \\
\text { centro cirúrgico para } \\
\text { pacientes COVID- } \\
19 .\end{array}$ & $\begin{array}{l}\text { Apresentar orientações } \\
\text { que proporcionem as } \\
\text { condições adequadas de } \\
\text { assistência e segurança } \\
\text { para os profissionais de } \\
\text { saúde na prevenção de } \\
\text { transmissão da infecção } \\
\text { humana pelo SARS- } \\
\text { CoV2, no centro cirúrgico. }\end{array}$ & $\begin{array}{l}\text { Foram encontrados } 19 \text { artigos na base de } \\
\text { pesquisa. Após a leitura dos resumos, foram } \\
\text { selecionados seis artigos, dos quais houve } \\
\text { acesso a cinco textos completos, além de quatro } \\
\text { outros escolhidos por divulgação, totalizando } \\
\text { nove artigos completos. Adicionalmente, foram } \\
\text { incluídas normas regulamentadoras e técnicas } \\
\text { oficiais. }\end{array}$ \\
\hline 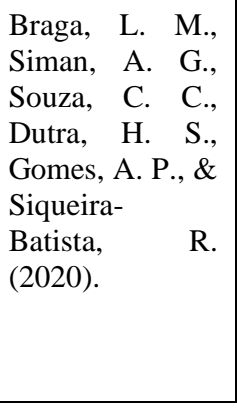 & $\begin{array}{l}\text { Revista de } \\
\text { Enfermagem } \\
\text { do Centro- } \\
\text { Oeste Mineiro } \\
\text { 2020;10:e407 } \\
\text { 9. }\end{array}$ & $\begin{array}{lr}\text { Construção } & \mathrm{e} \\
\text { validação } & \text { do } \\
\text { checklist } & \text { para } \\
\text { paramentação } & \text { e } \\
\text { desparamentação } & \\
\text { dos equipamentos } \\
\text { de proteção } \\
\text { individual. }\end{array}$ & $\begin{array}{l}\text { Descrever a construção e } \\
\text { validação de um checklist, } \\
\text { para paramentação e } \\
\text { desparamentação dos } \\
\text { equipamentos de proteção } \\
\text { individual (EPI), pelos } \\
\text { profissionais de saúde para } \\
\text { a prevenção da } \\
\text { autocontaminação por } \\
\text { agentes }\end{array}$ & $\begin{array}{l}\mathrm{Na} \text { etapa de validação, participaram } 20 \\
\text { profissionais de saúde sendo a maioria mulher, } \\
\text { com idades média de } 36,7 \text { anos, graduados em } \\
\text { enfermagem, medicina e odontologia, que } \\
\text { trabalham em instituições de saúde em Minas } \\
\text { Gerais, Rio de Janeiro e Paraná, ou, professores } \\
\text { de universidade pública e particular de Minas } \\
\text { Gerais. A } 1^{\circ} \text { versão do checklist dos EPIs atingiu } \\
\text { mais de } 80 \% \text { de concordância em todos os itens } \\
\text { de avaliação pelo comitê de especialistas. As } \\
\text { sugestões dos especialistas foram analisadas }\end{array}$ \\
\hline
\end{tabular}




\begin{tabular}{|c|c|c|c|c|}
\hline & & & $\begin{array}{l}\text { infectocontagiosos como o } \\
\text { SARS-CoV-2. }\end{array}$ & $\begin{array}{l}\text { pelo grupo focal on-line no formato de síncrono } \\
\text { que por fim concordaram com as sugestões nas } \\
\text { quais foram inseridos na versão final do } \\
\text { instrumento. }\end{array}$ \\
\hline $\begin{array}{l}\text { Lima, D. S., } \\
\text { Leite Filho, J. A. } \\
\text { D., Gurgel, M. } \\
\text { V. S. A., de } \\
\text { Aguiar Neto, A. } \\
\text { F., da Costa, E. } \\
\text { D. F. M., Maia } \\
\text { Filho, F. X. F., } \\
\text { Castro M. V., } \\
\text { Diniz, A. G., de } \\
\text { Oliveira Borges, } \\
\text { G. C., \& Junior, } \\
\text { M. A. F. R. } \\
\text { (2020). }\end{array}$ & $\begin{array}{l}\text { J Health Biol } \\
\text { Sci. } 2020 \quad J \\
8(1): 1-3 .\end{array}$ & $\begin{array}{l}\text { Recomendações } \\
\text { para cirurgia de } \\
\text { emergência durante } \\
\text { a pandemia do } \\
\text { COVID-19. }\end{array}$ & $\begin{array}{l}\text { O objetivo deste trabalho é } \\
\text { orientar a assistência } \\
\text { médica para os casos de } \\
\text { emergência cirúrgica não } \\
\text { traumática durante a } \\
\text { pandemia do COVID-19. }\end{array}$ & $\begin{array}{l}\text { Com a escassez de publicações especificas sobre } \\
\text { o manejo cirúrgico de paciente infectados pela } \\
\text { COVID-19 ou suspeitos, e tendo apenas } \\
\text { algumas orientações publicadas pela Sociedade } \\
\text { Espanhola de Cirurgia, Colégio Americano de } \\
\text { Cirurgiões, Sociedade Americana de Cirurgiões } \\
\text { Gastrintestinais e Endoscopistas, Sociedade } \\
\text { Brasileira de Atendimento Integrado ao } \\
\text { Traumatizado, além de um único artigo com } \\
\text { experiência medica publicado na China e Itália. } \\
\text { Foram elaboradas recomendações com base } \\
\text { nessas orientações, podendo ser aplicadas no } \\
\text { cenário local de assistência de saúde em rede } \\
\text { privada ou pública. Tais recomendações estão } \\
\text { sujeitas a } \\
\text { uma revisão contínua dependendo da situação } \\
\text { mundial da pandemia e das necessidades locais. }\end{array}$ \\
\hline $\begin{array}{l}\text { NECIH/COVIM } \\
\text { /DIVISA, } 2020 .\end{array}$ & $\begin{array}{ll}\text { Governo } & \text { do } \\
\text { estado } & \text { da } \\
\text { Bahia; } & \\
\text { Secretaria } & \text { da } \\
\text { Saúde } & \text { do } \\
\text { Estado } & \text { da } \\
\text { Bahia } & \\
\text { Diretoria } & \text { de } \\
\text { Vigilância } & \\
\text { Sanitária } & \text { e } \\
\text { Ambiental. } & \end{array}$ & $\begin{array}{l}\text { NOTA TÉCNICA } \\
\text { No 01/2020 } \\
\text { NECIH/COVIM/DI } \\
\text { VISA. Medidas de } \\
\text { prevenção e controle } \\
\text { que devem ser } \\
\text { adotadas durante a } \\
\text { assistência aos casos } \\
\text { suspeitos au } \\
\text { confirmados de } \\
\text { Infecção pelo novo } \\
\text { corona } \\
\text { COVID -2019. }\end{array}$ & $\begin{array}{l}\text { Fornecer medidas de } \\
\text { prevenção e controle que } \\
\text { devem ser adotadas } \\
\text { durante a assistência aos } \\
\text { casos suspeitos ou } \\
\text { confirmados de infecção } \\
\text { pelo novo corona vírus } \\
\text { COVID-19. }\end{array}$ & $\begin{array}{l}\text { As medidas de prevenção e controle de infecção } \\
\text { devem ser implementadas pelos profissionais } \\
\text { que atuam nos serviços de saúde para evitar ou } \\
\text { reduzir ao máximo a transmissão de } \\
\text { microrganismos durante qualquer assistência à } \\
\text { saúde realizada. Nesta nota técnica, serão } \\
\text { abordadas orientações para os serviços de saúde } \\
\text { públicos e privados, quanto as medidas de } \\
\text { prevenção e controle que devem ser adotadas } \\
\text { durante a assistência aos casos suspeitos ou } \\
\text { confirmados de infecção pelo novo coronavírus. } \\
\text { As medidas devem ser implementadas no } \\
\text { deslocamento do paciente ao serviço de saúde, } \\
\text { na chegada do mesmo ao serviço de saúde, na } \\
\text { espera do atendimento e durante toda a } \\
\text { assistência prestada. Recomendações, como } \\
\text { confeccionar o Protocolo Institucional de } \\
\text { Medidas Preventivas e de Controle para os casos } \\
\text { suspeitos ou confirmados de infecção pelo novo } \\
\text { coronavírus, realizar capacitação para todos os } \\
\text { trabalhadores de saúde, e orientações para } \\
\text { pacientes, acompanhantes e visitantes quanto as } \\
\text { precauções, educação permanente da população } \\
\text { quanto a importância do cumprimento das boas } \\
\text { práticas das precauções adotadas, estabelecer } \\
\text { critérios claros de triagem conforme a definição } \\
\text { de caso suspeito ou confirmado do novo } \\
\text { coronavírus. }\end{array}$ \\
\hline $\begin{array}{l}\text { Miranda, F. M. } \\
\text { D. A., de Lima } \\
\text { Santana, L., } \\
\text { Pizzolato, A. C., } \\
\text { \& Sarquis, L. M. } \\
\text { M. (2020). }\end{array}$ & $\begin{array}{l}\text { Cogitare } \\
\text { enfermagem, } \\
25 .\end{array}$ & $\begin{array}{l}\text { Condições de } \\
\text { trabalho e o impacto } \\
\text { na saúde dos } \\
\text { Profissionais de } \\
\text { enfermagem frente a } \\
\text { COVID-19. }\end{array}$ & $\begin{array}{l}\text { Refletir sobre as condições } \\
\text { de trabalho dos } \\
\text { profissionais } \\
\text { enfermagem de } \\
\text { enfrentamento ao novo } \\
\text { coronavírus e apontar o } \\
\text { impacto na vida desses } \\
\text { profissionais em meio à } \\
\text { pandemia. }\end{array}$ & $\begin{array}{l}\text { Atualmente os profissionais de enfermagem } \\
\text { vivem, jornadas extensas de trabalho, } \\
\text { desvalorização profissional, desgaste físico e } \\
\text { psíquico, entre outros, e com o desencadear da } \\
\text { pandemia foi potencializado com a carência de } \\
\text { EPIs adequados, logo são fatores que } \\
\text { contribuem para o desgaste o medo de infectar } \\
\text { a si mesmo ou familiares. De acordo, com o } \\
\text { observatório do conselho federal de } \\
\text { enfermagem, foram registrados elevados } \\
\text { números de profissionais de enfermagem } \\
\text { afetados pelo vírus, esses dados mostram a } \\
\text { necessidade de medidas que protejam esses } \\
\text { profissionais de forma mais integral, e que } \\
\text { coloquem em pratica protocolos que diminuam }\end{array}$ \\
\hline
\end{tabular}




\begin{tabular}{|c|c|c|c|c|}
\hline & & & & $\begin{array}{l}\text { o risco de contaminação durante o trabalho. A } \\
\text { atuação do enfermeiro durante a pandemia } \\
\text { ganhou destaque nas ações de vigilância, } \\
\text { prevenção, controle de transmissão do vírus, } \\
\text { assistência aos doentes, nas pesquisas sobre tal } \\
\text { enfermidade, além de estar atenta aos cuidados } \\
\text { com a família, coletividade de forma empática. }\end{array}$ \\
\hline $\begin{array}{l}\text { Oliveira, E. C. } \\
\text { D. S., Silva, F. } \\
\text { P. D., Pereira, E. } \\
\text { B. F., \& } \\
\text { Oliveira, R. C. } \\
\text { D. (2020). }\end{array}$ & $\begin{array}{l}\text { Rev. baiana } \\
\text { enferm. }\end{array}$ & $\begin{array}{l}\text { Ações da comissão } \\
\text { de controle de } \\
\text { infecção hospitalar } \\
\text { frente ao novo } \\
\text { coronavírus. }\end{array}$ & $\begin{array}{l}\text { Relatar a experiência } \\
\text { vivenciada por } \\
\text { enfermeiros executores da } \\
\text { CCIH no combate ao novo } \\
\text { coronavírus, em um } \\
\text { hospital público de grande } \\
\text { porte. }\end{array}$ & $\begin{array}{l}\text { Na vivência prática do trabalho intra-hospitalar } \\
\text { ao combate à COVID-19, a equipe de saúde vem } \\
\text { apresentando sinais de adoecimento físico e } \\
\text { mental, provavelmente pelo excesso de trabalho } \\
\text { e medo do desconhecido. Observam-se também } \\
\text { as emergentes mudanças no processo de trabalho } \\
\text { dos profissionais de saúde. }\end{array}$ \\
\hline $\begin{array}{l}\text { Borges, I. V., de } \\
\text { Jesus Bernardes, } \\
\text { A., Borges, T. R. } \\
\text { R., \& Barreto, R. } \\
\text { A. D. S. S. } \\
(2021) .\end{array}$ & $\begin{array}{l}\text { Saúde } \\
\text { Coletiva }\end{array}$ & $\begin{array}{l}\text { Assistência em } \\
\text { enfermagem ao } \\
\text { paciente cirúrgico } \\
\text { com diagnóstico de } \\
\text { SARS-COV2: } \\
\text { revisão integrativa } \\
\text { da literatura }\end{array}$ & $\begin{array}{l}\text { Relatar sobre as principais } \\
\text { recomendações e cuidados } \\
\text { que a equipe de saúde } \\
\text { deverá implementar frente } \\
\text { aos pacientes positivos } \\
\text { para Covid-19 durante o } \\
\text { período perioperatório. }\end{array}$ & $\begin{array}{l}\text { Devido ao momento de pandemia que o mundo } \\
\text { está vivendo, os serviços de saúde tiveram que } \\
\text { se moldar de acordo com as recomendações } \\
\text { preconizadas. O centro cirúrgico passou por } \\
\text { algumas adaptações, dando prioridade para } \\
\text { procedimentos de urgência/emergência e } \\
\text { reavaliando a necessidade das cirurgias eletivas. }\end{array}$ \\
\hline ANVISA, 2020. & $\begin{array}{l}\text { ANVISA/ } \\
\text { MS. }\end{array}$ & 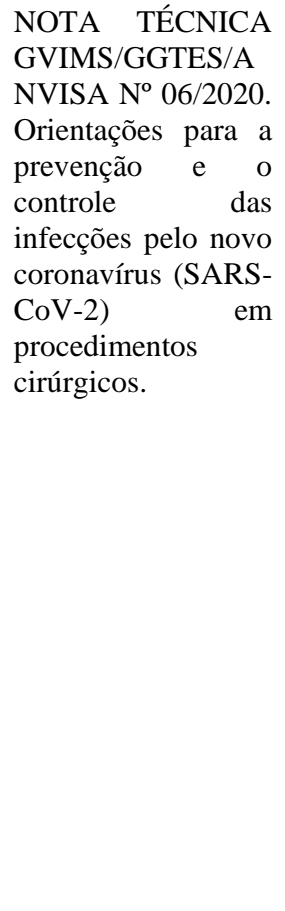 & $\begin{array}{l}\text { Orientar quanto a } \\
\text { prevenção e o controle das } \\
\text { infecçôes pelo novo } \\
\text { coronavírus } \\
\text { 2) em paRS-CoV- } \\
\text { cirúrgicos. }\end{array}$ & $\begin{array}{l}\text { Tais orientações se baseiam em alguns aspectos } \\
\text { como a organização cirúrgica, sendo necessária } \\
\text { somente a priorização de cirurgias eletivas } \\
\text { essenciais, atentando-se a composição da equipe } \\
\text { para que não exceda o limite, assim como se } \\
\text { deve identificar a presença de qualquer } \\
\text { profissional sintomático, o qual não deve } \\
\text { participar do ato operatório. Discorre-se também } \\
\text { sobre a capacitação da equipe a fim de melhorar } \\
\text { a assistência e treinar os vários cenários } \\
\text { possíveis. Quanto a equipamentos de proteção } \\
\text { individual é imperativo que haja equipamento de } \\
\text { proteção individual (EPI) para toda a equipe, } \\
\text { adequado para o atendimento de pacientes } \\
\text { suspeitos e confirmados de COVID-19. No } \\
\text { ambiente cirúrgico é importante a adoção de } \\
\text { Protocolos e "Checklists" específicos, } \\
\text { considerar definição de salas de cirurgias } \\
\text { exclusivas para pacientes suspeitos ou } \\
\text { confirmados com COVID-19, reforçar as } \\
\text { orientações de que objetos pessoais (bolsas, } \\
\text { carteiras, chaves, etc) não devem ser levados } \\
\text { para o ambiente cirúrgico. Restringir o } \\
\text { quantitativo de pessoas em sala operatória (SO) } \\
\text { durante a intubação orotraqueal. }\end{array}$ \\
\hline $\begin{array}{l}\text { Batista, J. R., } \\
\text { Leite, K. N. S., } \\
\text { Oliveira, S. X., } \\
\text { Medeiros, R. C. } \\
\text { D., Souza, T. A. } \\
\text { D., \& Lima, M. } \\
\text { M. G. D. (2017). }\end{array}$ & $\begin{array}{l}\text { Rev. enferm. } \\
\text { UFPE on line. }\end{array}$ & $\begin{array}{l}\text { Conhecimento da } \\
\text { equipe de } \\
\text { enfermagem perante } \\
\text { os principais tipos } \\
\text { de infecções } \\
\text { hospitalares. }\end{array}$ & $\begin{array}{l}\text { Identificar } \\
\text { conhecimento da equipe } \\
\text { de enfermagem perante as } \\
\text { infecções hospitalares. }\end{array}$ & $\begin{array}{l}100 \% \text { dos enfermeiros e } 96,7 \% \text { dos técnicos de } \\
\text { enfermagem têm conhecimento sobre a infecção } \\
\text { hospitalar; } 80 \% \text { dos enfermeiros e } 70 \% \text { dos } \\
\text { técnicos de enfermagem usam o EPI } \\
\text { (Equipamento de Proteção Individual) } \\
\text { corretamente. }\end{array}$ \\
\hline $\begin{array}{l}\text { Ribeiro, P. A., } \\
\text { Oliveira, G. L., } \\
\text { Silva, L. S. } \\
\text { Souza, E. R., } \\
(2020)\end{array}$ & $\begin{array}{l}\text { Revista } \\
\text { Brasileira de } \\
\text { Saúde } \\
\text { Ocupacional } \\
\text { 2020; 45:e25 }\end{array}$ & $\begin{array}{lr}\text { Saúde e segurança } \\
\text { de profissionais } & \text { de } \\
\text { saúde } & \text { no } \\
\text { atendimento } & \text { a } \\
\text { pacientes } & \text { no } \\
\text { contexto } & \text { da } \\
\text { pandemia de Covid- } \\
\text { 19: revisão } & \text { de } \\
\text { literatura. } & \end{array}$ & $\begin{array}{l}\text { Analisar a produção } \\
\text { científica sobre a saúde } \\
\text { dos trabalhadores da saúde } \\
\text { que atendem pacientes no } \\
\text { contexto da pandemia de } \\
\text { COVID-19. }\end{array}$ & $\begin{array}{l}\text { Na etapa final, foram analisados } 52 \text { documentos } \\
\text { focalizados em trabalhadores atuantes em } \\
\text { hospitais, como médicos, enfermeiros, } \\
\text { profissionais atuantes em especialidades } \\
\text { especificas médicas e outros profissionais da } \\
\text { área da saúde. Uma parcela dos entrevistados da } \\
\text { área da saúde que trabalham em hospitais } \\
\text { mostram que os mesmos estão mais propícios a } \\
\text { infecção pela covid-19. Trabalhar na linha de } \\
\text { frente para uma quantidade significativa de }\end{array}$ \\
\hline
\end{tabular}




\begin{tabular}{|c|c|c|c|c|}
\hline & & & & $\begin{array}{l}\text { profissionais tem ocasionado transtornos } \\
\text { mentais incluindo depressão, ansiedade, } \\
\text { angústia e medo, pois a pandemia da covid-19 } \\
\text { favoreceu para o desgaste dos profissionais da } \\
\text { saúde. Contudo, segundo os estudos mostraram } \\
\text { que a utilização de EPI pelos profissionais de } \\
\text { saúde reduz os riscos de infecção por COVID- } \\
19 \text {, porém para que seja eficaz precisa que os } \\
\text { profissionais estejam treinados de como utilizá- } \\
\text { los corretamente. }\end{array}$ \\
\hline $\begin{array}{l}\text { Sousa, C. S., } \\
\text { acuña, A. A., } \\
(2020) .\end{array}$ & $\begin{array}{l}\text { Revista } \\
\text { Associação } \\
\text { Brasileira de } \\
\text { Enfermeiros } \\
\text { de Centro } \\
\text { Cirúrgico, } \\
\text { Recuperação } \\
\text { Anestésica e } \\
\text { Centro de } \\
\text { Material e } \\
\text { Esterilização } \\
\text { (SOBECC). } \\
\text { 2020; 25(4): } \\
\text { 195-196. }\end{array}$ & $\begin{array}{lr}\text { Treinamento } & \text { e } \\
\text { qualificação dos } \\
\text { profissionais de } \\
\text { enfermagem do } \\
\text { bloco cirúrgico para } \\
\text { atendimento de } \\
\text { pacientes infectados } \\
\text { com coronavírus } \\
\text { sars-cov-2 em áreas } \\
\text { externas. }\end{array}$ & $\begin{array}{l}\text { Realocação } \\
\text { profissionais de } \\
\text { treinamentos para a } \\
\text { atuação no serviço de alta } \\
\text { demanda da covid-19. }\end{array}$ & $\begin{array}{l}\text { No período da pandemia do sars-cov- } 2 \text {, cirurgias } \\
\text { foram afetadas diretamente, havendo mudanças } \\
\text { nas cirurgias e nas urgências, focando assim na } \\
\text { covid-19, com isso mudando a área de atuação } \\
\text { de muitos profissionais de saúde para o } \\
\text { atendimento dos pacientes, onde a pandemia } \\
\text { veio para mudar e trazer um novo olhar de } \\
\text { cuidado inovação e comunicação entre as } \\
\text { equipes da saúde. }\end{array}$ \\
\hline
\end{tabular}

Fonte: Autores (2021).

Por meio da Classificação Hierárquica Descendente (CHD) o software IRAMUTEQ reconheceu nesta pesquisa 138 segmentos de textos (ST) e manteve 98 destes seguimentos, obtendo o total de 71,01\% de aproveitamento. A partir disso, sucedeu a divisão do corpus em 6 classes, na qual a classe 1 corresponde a 16,3\% de palavras no corpus, a classe 2 corresponde a 18,4\%, a classe 3 corresponde a $14,3 \%$, a classe 4 corresponde a $21,4 \%$, a classe 5 corresponde a $14,3 \%$ e a classe 6 corresponde a $15,3 \%$.

Com base na leitura das palavras destacadas nos ST, foi realizado a formação de categorias que alcançou o objetivo do estudo em caracterizar a atuação do enfermeiro para prevenir infecções pelo SARS-CoV-2 no centro cirúrgico durante a pandemia da Covid-19. Segue em anexo na Figura 2 o dendrograma com a formação das classes: 
Figura 2: Dendograma fornecido pelo software IRAMUTEQ - 2021.

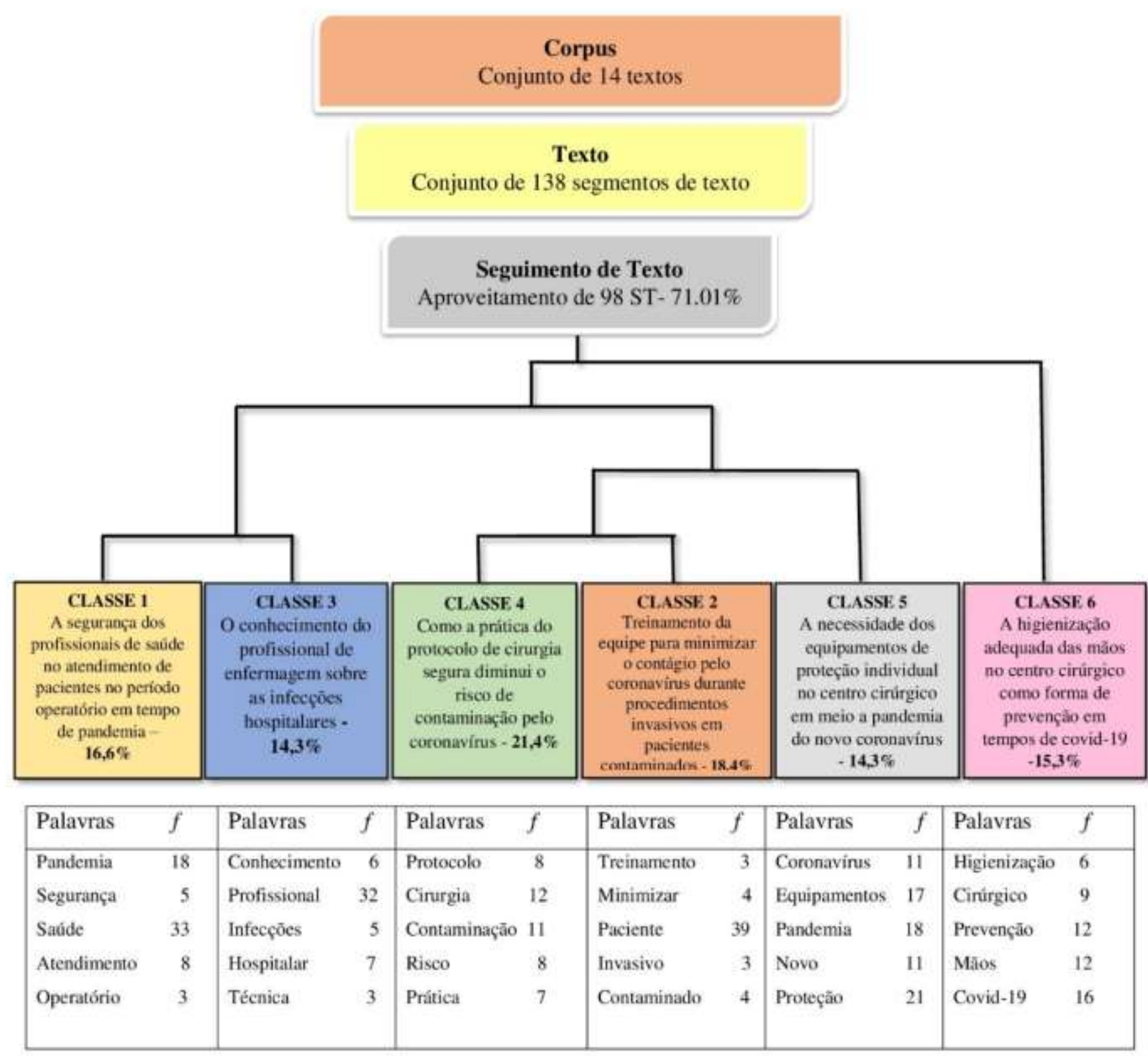

Fonte: Autores (2021).

\section{Discussão}

\section{Categoria 1: O conhecimento do profissional de enfermagem sobre as infecções hospitalares}

As infecções relacionadas à assistência em saúde (IRAS) são mundialmente consideradas um grave problema de saúde pública, pois representa complicações referente à assistência de saúde e consiste na principal causa de morbidade e mortalidade, e do prolongamento de internação. O Ministério da Saúde define infecção hospitalar como aquela adquirida após a internação, que se manifesta durante a internação do paciente, ou após a alta quando se pode relacionar a infecção com a internação ou procedimentos hospitalares (Rocha \& Lages, 2016).

Um dos pilares fundamentais da assistência em saúde de qualidade é a segurança do paciente, a assistência segura é protagonista em discussões da área da saúde no mundo todo. O Ministério da Saúde no Brasil, lançou na portaria nº 529 de 2013 
o Programa Nacional de Segurança do Paciente (PNSP), que tem em seus objetivos a qualificação do cuidado em saúde, o apoio à implementação de práticas seguras, com base nos protocolos básicos, a fim de promover uma cultura de segurança nas instituições de saúde. Diante desse cenário, a enfermagem possui uma relação direta com a temática, em vista disso, é reconhecida como a maior força de trabalho. Portanto, é essencial enfatizar o olhar clínico e o conhecimento do enfermeiro nos cuidados prestados durante sua assistência, visto que é o profissional no qual assume o cuidado direto, pela maior parte do tempo (da Guarda et al. 2020). De acordo com, do Espiríto Santo et al (2019), o profissional de enfermagem é o responsável pela assistência ao paciente, por guiar a equipe de enfermagem e administrar os recursos físicos, materiais e humanos. Sua atuação é fundamentada no cuidado direto e indireto com o paciente.

Segundo Rocha e Lages (2016) 80\% das infecções hospitalares são causadas pela flora do próprio paciente, sendo que $20 \%$ são transmitidas pelas mãos dos profissionais de saúde, pelos artigos médico-hospitalares contaminados, equipamentos e ambiente. Além do mais, os profissionais de saúde contribuem para propagação dos microrganismos e para autoinfecção por não utilizarem as técnicas assépticas e sépticas corretamente. Do Espírito Santos et al (2019) ressalta a importância do conhecimento dos profissionais de saúde acerca da microbiota, assepsia, desinfecção e esterilização, como também acerca do preparo dos materiais e equipamentos cirúrgicos. Em vista disso, a melhor forma de manter os profissionais atualizados e capacitados é por meio da educação permanente, no qual o enfermeiro possui a atribuição importante de repassar seu conhecimento científico para sua equipe.

\section{Categoria 2: A segurança dos profissionais de saúde no atendimento de pacientes no período operatório em tempo de pandemia}

Nos últimos anos o Brasil vivencia a grande desvalorização dos trabalhadores da área da saúde, principalmente nos serviços públicos, embora atualmente a crise sanitária revela a extrema importância desses trabalhadores para a população. Uma pandemia exige que os serviços de saúde respondam prontamente para as demandas nas quais não estão preparados. Diante do cenário da pandemia da Covid-19 a jornada de trabalho sofreu alterações relacionada às horas extras e ao ritmo de trabalho, os trabalhadores na linha de frente do combate ao coronavírus e que estão em contato direto com pessoas são os mais expostos a contrair a Covid-19 (Helioterio et al. 2020).

Para Nunes et al (2021) os cuidados com a infecção intra-hospitalar devem ser intensificados no atual cenário, além de observar em pacientes cirúrgicos a real necessidade de operação, e por segurança deve-se adiar cirurgias eletivas. O período operatório possui um risco potencial de contaminação da equipe, a infeção pode ocorrer de forma comum como no contato pelas gotículas, contudo, a grande preocupação é durante a cirurgia no momento da intubação traqueal, pela produção de aerossóis (Parreira et al. 2020). Logo, os profissionais de saúde estão mais sujeitos a ter contato com o vírus no ambiente cirúrgico, devida a combinação de instrumentos elétricos, a dispersão de gases em laparoscopias, respingos de sangue em alta velocidade e sistemas de ventilação positiva, podendo receber uma grande carga viral. Desse modo, os profissionais devem estar protegidos com EPIs adequados, inclusive deve-se considerar que todos os pacientes cirúrgicos estão infectados pelo vírus, para que sejam tomadas as devidas precauções (Nunes et al. 2021).

$\mathrm{O}$ ambiente de trabalho seguro requer a melhoria das condições de trabalho, a redefinição de séries assistenciais e instituição de protocolos de rotina para recomendações de controle da Covid-19. Deve ser implementado medidas coletivas e individuais, além de ofertar equipamentos de proteção individual, é essencial a reorganização do processo de trabalho, no intuito de reduzir o risco de infecção. É indispensável também as medidas gerais como redistribuir o número de trabalhadores nos ambientes e nos horários de maior circulação, adequar os processos e ambientes de trabalho com as novas escalas e rodízios, treinamentos para simplificar os modos operatórios e ofertar apoio psicológico aos profissionais. (Helioterio et al. 2020) 
Portanto, em concordância com Helioterio et al (2020) que diz que a luta contra a Covid-19 requer quantidade e qualidade de profissionais de saúde, os pacientes infectados em estado grave necessitam de tecnologias e procedimentos de alta complexidade, o que exige profissionais treinados e qualificados. Sendo assim, preservar a vida e a saúde dos profissionais de saúde garante a oferta de cuidados em saúde à população.

\section{Categoria 3: A necessidade dos equipamentos de proteção individual no centro cirúrgico em meio a pandemia do novo coronavírus}

Com a pandemia do novo coronavírus (SARS-CoV-2), doença chamada COVID-19, vem acarretando consigo diversos problemas de saúde, sendo eles agudos e graves, configurando assim, uma crise de saúde pública mundial (Helioterio et al. 2020). Dentre as ações que visam a proteção dos profissionais de saúde frente a assistência a pacientes infectados, estão o fornecimento de equipamentos de proteção individual (EPIs), capacitação das equipes para o uso adequado destes equipamentos como paramentação e desparamentação adequada, visto que são muitos os desafios encontrados diante da exposição e dos riscos a que estes profissionais estão expostos. (Silva R, Silva M,2020).

Conceitualmente o uso dos EPI destinam-se a proteção dos profissionais sobre os fatores de risco no ambiente hospitalar. Dessa forma, luvas, máscaras, aventais e outros, não alteram o fator de risco presente no ambiente ou impedem ações perigosas. Porém, agem como minimizador dos efeitos ou consequências de um processo acidental ou o aparecimento de comorbidades. (Saraiva et al. 2020). Contudo, o EPI é o principal método de barreira para manter a integralidade da saúde dos profissionais que estão em contato direto aos pacientes da covid-19. (Alves, J. R. (2020).

Portanto, os equipamentos de proteção individual são imprescindíveis e devem serem priorizadas pelos profissionais da saúde, durante a sua assistência, assim como os procedimentos cirúrgicos, tendo em vista a redução dos riscos aos profissionais e pacientes assim como a minimização dos riscos de infecção. (Lima et al, 2020).

\section{Categoria 4: A higienização adequada das mãos no centro cirúrgico como forma de prevenção em tempos de covid-19}

Devido a pandemia da covid-19, surge a necessidade de enfatizar medidas de prevenção no ambiente hospitalar, como uso de antissépticos de forma a minimizar ou evitar a proliferação de infecções hospitalares, haja vista que, as mãos são os principais meios de contaminação, onde abrigam microrganismos e os transferem de uma superfície a outra. (Ferreira et al, 2020). A escolha e o uso eficaz do antisséptico pode minimizar a ocorrência de infecções relacionadas aos pacientes hospitalizados, assim, a higienização das mãos adequada é imprescindivelmente importante para que haja uma redução dos microrganismos que colonizam a pele. (Menezes et al, 2016)

Diante da relevância das mãos como instrumentos de propagação de septicemia e de transmissão das Infecções Associadas aos Cuidados em Saúde (IACS), fomenta-se também que uma adequada higienização das mãos, diminui os riscos de contaminações, tendo em vista que, muitos profissionais acabam sendo passivos e ao mesmo tempo os serviços de saúde adotam meios ineficientes de campanhas educativas de HM (Ferreira et al, 2020).

A transmissão do novo coronavírus se dá através de contato direto, onde ocorre a inserção do vírus nas mucosas (nariz, olhos ou boca) e consequentemente do contato com locais contaminados, o que traz um olhar mais abrangente sobre as necessidades de prevenção, onde venham trazer medidas que visem a disseminação da contaminação entre a população (Ferreira et al, 2020).

Portanto, à medida que ajuda a minimizar a transmissão da covid-19 está relacionada a higienização das mãos, onde a mesma é de baixo custo e alta indubitabilidade, pois as mãos são os principais instrumentos de contaminação (Oliveira et al, 2020). 


\section{Categoria 5: Treinamento da equipe para minimizar o contágio pelo coronavírus em procedimentos invasivos}

Em 02 de março de 2020 foi registrado no Brasil o primeiro caso de coronavírus, e então houve o aumento acelerado do vírus na população, sendo necessário medidas para controlar a disseminação da doença (Rafael et al 2020). Nesse contexto as Instituições de saúde precisam dimensionar a quantidade de pessoas e prover contratação de novos trabalhadores, o que demandou o desenvolvimento implementação de medidas para o preparo desses profissionais. Levando em consideração que a falta de treinamento afeta diretamente a produtividade, com evidente impacto na qualidade da assistência prestada a proposta de treinamento tem como objetivo preparar os profissionais da equipe para uma assistência que esteja baseada em processos, protocolos e diretrizes (Matsubara et al 2020).

Frente a pandemia as instituições devem oferecer programas temos que aprimorar os conhecimentos sobre a COVID19 afim de prestar um cuidado apropriado. (Matsubara et al 2020). À equipe de enfermagem é a principal linha de frente para a recepção do paciente cirúrgico, sendo que a assistência a esse depende de vários processos, portanto a capacitação dos profissionais inicia desde a definição e provisão da sala de cirurgia, bem como dos materiais que serão utilizados. Para procedimentos invasivos em pacientes suspeitos ou confirmados de COVID-19 é necessário medidas de precaução de contato e por aerossol. (Fonseca; Rocha; Portugal 2020).

No entanto apesar da necessidade de capacitação nesse período da pandemia existem barreiras que dificultam o envolvimento dos profissionais que participam nesse processo, porém o mesmo é de suma importância visto que possibilita a construção de informações com a finalidade de facilitar o conhecimento da equipe sobre as formas de prevenção e controle de infecções pela COVID-19 em procedimentos invasivos (Fonseca; Rocha; Portugal 2020).

\section{Categoria 6: Como a prática do protocolo de cirurgia segura diminui o risco de contaminação pelo coronavírus}

$\mathrm{O}$ acontecimento de incidentes é tido como um problema sério o qual está relacionado à segurança do paciente bem como a qualidade do cuidado prestado. A Organização Mundial da Saúde (OMS) calcula que cerca de 10\% dos pacientes sofrem com falhas que estão relacionadas aos cuidados hospitalares (Simon; Brito 2016).

Em decorrência de alguns aspectos as salas de cirurgia são consideradas ambientes com alto risco o que estão sujeitos a erros. As complicações cirúrgicas são os responsáveis pela maior parcela de óbitos e danos, os quais são na maioria das vezes causados pelo processo de assistência, portanto são evitáveis. Por essa razão em 2004 a OMS lançou uma campanha intitulada "cirurgia segura salvam vidas" como parte da Aliança Mundial Para a Segurança do Paciente, tal ação se deu para estimular a conscientização pelos profissionais de saúde, assim como o compromisso para a melhora dos cuidados de saúde (Gutierres et al., 2018).

A equipe de enfermagem é a maior responsável pela aplicação do checklist do protocolo de cirurgia segura, fazendo o jus as orientações para a segurança do paciente, essas desempenham um importante papel no perioperatório sendo fundamentais para passar confiança e segurança ao paciente, portanto é importante que os profissionais estejam capacitados quanto aos conhecimentos teóricos e técnicos (Oliveira et al., 2017).

A Covid-19 trouxe mudanças no cenário epidemiológico o que exige medidas de adaptação para minimizar os danos que foram provocados pela pandemia. Nos centros cirúrgicos é levado a chance de contágio paciente-profissional profissionalpaciente, devido a manipulação das vias aéreas bem como procedimentos anestésicos e a dificuldade de comunicação entre os membros da equipe (Santos 2020).

Houve a suspensão de procedimentos eletivos priorizando apenas cirurgia urgência e emergência para que assim fosse priorizados leitos para pacientes com infecção respiratória. Desse modo o planejamento para a retomada dos procedimentos cirúrgicos deve ser baseado em novos protocolos que visam prevenir e controlar a transmissão do novo coronavírus nos serviços de saúde (Forrester et al., 2020). 
O paciente cirúrgico normalmente é vulnerável a erros nos cuidados, principalmente durante a pandemia da COVID19, o que possibilitou o surgimento da discussão a respeito da adaptação da lista de verificação de cirurgia segura a essa nova realidade, com o objetivo de agregar as especificidades relativas a procedimentos na pessoa em isolamento respiratório, a fim de prestar uma assistência que englobe pacientes e profissionais (Oliveira; Gonçalves; Lima 2020).

A prática do protocolo de cirurgia segura o qual engloba a lista de verificação de cirurgia segura (checklist) contribui para nortear assistência e também como instrumentos práticos de supervisão, o qual auxilia os profissionais na organização do cuidado, evitando o desperdício de insumos, otimização da equipe bem como a prevenção de contaminação pela COVID-19. tal instrumento se constitui como um meio relevante de promoção da segurança do paciente durante a assistência cirúrgica na vigência da pandemia da COVID-19 na necessidade de se manter os procedimentos cirúrgicos bem como assistência segura (Oliveira; Gonçalves; Lima 2020).

\section{Conclusão}

Dado o exposto conclui-se que devido às mudanças epidemiológicas que um mundo sofreu em decorrência da pandemia da COVID-19 O centro cirúrgico precisou se reorganizar para atender a demanda desse novo cenário, garantindo a segurança dos pacientes e da equipe multiprofissional. É indiscutível o papel da enfermagem dentro desse contexto, pois é uma das profissões em que há maior convívio junto aos pacientes e nesse sentido é importante que esta realize medidas específicas para a prevenção da disseminação de microrganismos no ambiente hospitalar, sobretudo no centro cirúrgico em vigência da pandemia da COVID-19.

Ações básicas tais como o uso correto dos EPI's, higienização adequada das mãos até o treinamento da equipe para o manuseio de pacientes com COVID-19 e a adesão ao protocolo de cirurgia segura se fazem grandes aliados no que tange à prevenção e controle da transmissão do novo coronavírus. Portanto pretende-se que esse artigo contribua para fomentar a discussão e a reflexão sobre quais devem ser as decisões tomadas para o controle da disseminação do novo coronavírus, tanto por parte dos profissionais quanto dos gestores das instituições de saúde, na tentativa de prestar uma assistência segura tanto para pacientes quanto para os profissionais que atuam no centro cirúrgico como linha de frente nessa pandemia.

Portanto sugere-se a continuidade de estudos desse gênero, visto que a temática abordada é de extremo enriquecimento científico para os diferentes âmbitos dos setores da saúde e profissionais da área, principalmente em detrimento da atual realidade da pandemia da COVID-19. Vale ressaltar ainda, a carência de estudos referente Atuação do enfermeiro para prevenção de infecções pela SARS- CoV2 no centro cirúrgico durante a pandemia da COVID-19 devido ser uma pauta muito atual, justificando assim possíveis fragilidades do estudo apresentado. Logo, torna-se evidente a necessidade da elaboração de mais pesquisas no que tange a temática explorada, finalizando, é de grande valia para os profissionais da saúde que se reiterem a respeito das medidas de prevenção e protocolos de segurança que já eram e que estão sendo tomados principalmente devido à atual realidade de pandemia.

\section{Referências}

Alves, J. R. (2020). Recomendações em cirurgia durante a pandemia da Covid-19. Arquivos Catarinenses de Medicina, 49(1), 111-125.

ANVISA. (2020). NOTA TÉCNICA GVIMS/GGTES/ANVISA Nº 06/2020. Orientações para a prevenção e o controle das infecções pelo novo coronavírus (SARS-CoV-2) em procedimentos cirúrgicos. ANVISA/MS.

Batista, J. R., Leite, K. N. S., Oliveira, S. X., Medeiros, R. C. D., Souza, T. A. D., \& Lima, M. M. G. D. (2017). Conhecimento da equipe de enfermagem perante os principais tipos de infecções hospitalares. Rev. enferm. UFPE on line.

Borges, I. V., de Jesus Bernardes, A., Borges, T. R. R., \& Barreto, R. A. D. S. S. (2021). Assistência em enfermagem ao paciente cirúrgico com diagnóstico de SARS-COV2: revisão integrativa da literatura. Saúde Coletiva (Barueri), 11(62), 5154-5173 
Braga, L. M., Siman, A. G., Souza, C. C., Dutra, H. S., Gomes, A. P., \& Siqueira-Batista, R. (2020). Construção e validação do checklist para paramentação e desparamentação dos equipamentos de proteção individual. Revista de Enfermagem do CentroOeste Mineiro, 10:e4079.

Brasil. (2020). Brasil confirma primeiro caso da doença. Ministério da Saúde. https://www.saude.gov.br/noticias/agencia-saude/46435-brasil-confirma-primeirocaso-de-novo-coronavirus.

Busanello, J., da Silva Galetto, S. G., Harter, J., \& Garcia, R. P. (2020). Otimização dos cuidados intensivos na assistência ao paciente com COVID-19. Enfermagem em Foco, 11(2. ESP).

Correia, M. I. T. D., Ramos, R. F., \& Bahten, L. C. V. (2020). Os cirurgiões e a pandemia do COVID-19. Revista do Colégio Brasileiro de Cirurgiões, 47.

Cunha, A. G., Peixoto, T. L., Gomes, L. C. P., Bastos, V. D. S., Cavalcanti, T. P., \& Gusmão-Cunha, A. M. (2020). Como preparar o centro cirúrgico para pacientes COVID-19. Revista do Colégio Brasileiro de Cirurgiões, 47.

Da Guarda, A. F., Pôncio, T. H. G., Von Randow, R. M., \& Timoteo, M. P. (2021). Percepção dos enfermeiros sobre segurança do pacientem em tempos de pandemia da Covid-19. Anais do Seminário Científico do UNIFACIG, (6).

Do Espírito Santo, I. M., do Espírito Santo, P. M., de Lima Fontes, F. L., Santos, M. D. C. S. P., Freitas, E. P., Neta, A. D. S. S., Figueiredo, J. O., da Silva, F. J. A., Silva, L. J. G., Matos, D. R., Soares, J. C., Araújo, M. A., Pinho, L. F., Caland, M. H. M. G., \& de Araújo, E. V. (2019). Conhecimento do enfermeiro sobre o processo de trabalho na Central de Material de Esterilização. Revista Eletrônica Acervo Saúde, (20), e403-e403.

Ferreira, M. M. N., Passos, M. A. N., \& Ferraz, C. R. (2020). A enfermagem empregando a gamificação para a adesão à higienização das mãos, no combate ao covid-19. Revista JRG de Estudos Acadêmicos, 3(7), 274-284.

Fonseca, M. A. R., da Rocha, V. S., \& Portugal, F. B. (2021). Capacitacão da equipe de enfermagem para o atendimento cirúrgico em pacientes com casos confirmados ou suspeito de Covid-19: uma estratégia para a qualidade do cuidado. Atena editora 1- 388.

Forrester, J. D., Nassar, A. K., Maggio, P. M., \& Hawn, M. T. (2020). Precautions for operating room team members during the COVID-19 pandemic. Journal of the American College of Surgeons, 230(6), 1098-1101.

Gutierres, L. D. S., Santos, J. L. G. D., Peiter, C. C., Menegon, F. H. A., Sebold, L. F., \& Erdmann, A. L. (2018). Boas práticas de segurança do paciente na sala de cirurgia: recomendações dos enfermeiros. Revista brasileira de enfermagem, 71, 2775-2782.

Governo do estado da Bahia. (2020). NOTA TÉCNICA Nº 01/2020 NECIH/COVIM/DIVISA. Medidas de prevenção e controle que devem ser adotadas durante a assistência aos casos suspeitos ou confirmados de Infecção pelo novo coronavírus COVID -2019. Secretaria da Saúde do Estado da Bahia; Diretoria de Vigilância Sanitária e Ambiental.

Helioterio, M. C., Lopes, F. Q. R. D. S., Sousa, C. C. D., Souza, F. D. O., Pinho, P. D. S., Sousa, F. N., \& Araújo, T. M. D. (2020). Covid-19: Por que a proteção de trabalhadores e trabalhadoras da saúde é prioritária no combate à pandemia? Trabalho, Educação e Saúde, 18(3).

Jesus, M. R. C. D., Melo, M. G., Campos, M. P. D. A., Barbosa, T. O., Abud, A. C. F., \& Lordelo, D. D. S. (2020). Avaliação da adequação no uso da paramentação cirúrgica. Rev. SOBECC, 91-98.

Junior, L. S. B., Gemir, J. L., Coimbra, A. L. S., Honorato, J. C., de Ataide Caliari, V., Silva, A. A., \& de Azevedo Filho, H. R. C. O impacto da Covid-19 na rotina dos blocos cirúrgicos. Atena editora, 1-388.

Junior, R., Fontenelle, M. A., De-Campos, T. E. R. C. I. O., Lima, D. S., Marttos-JR, A. C., \& Pereira, B. M. (2020). O cirurgião de trauma e emergência na era da pandemia de COVID-19. Revista do Colégio Brasileiro de Cirurgiões, 47

Lima, D. S., Leite Filho, J. A. D., Gurgel, M. V. S. A., de Aguiar Neto, A. F., da Costa, E. D. F. M., Maia Filho, F. X. F., Castro M. V., Diniz, A. G., de Oliveira Borges, G. C., \& Junior, M. A. F. R. (2020). Recomendações para cirurgia de emergência durante a pandemia do COVID-19. J Health Biol Sci. 2020 J; 8(1):13 .

Matsubara, M. D. G. S., Soares, R. C., da Silva, E. F., Cascapera, F., Saraiva, D. A., da Silva, B. A., \& Cijevschi, E. C. (2020). Estratégias de treinamento admissional da equipe de Enfermagem de um Cancer Center durante a pandemia do COVID19. Enfermagem em Foco, 11(2. ESP)

Mendes, P. D. J. A., da Silveira, K. D. C. G., \& Morgan, P. E. M. (2020). Atuação Do Enfermeiro Na Prevenção De Eventos Adversos No Centro Cirurgico, Utilizando Saep. Bius-Boletim Informativo Unimotrisaúde em Sociogerontologia, 19(13), 1-17.

Melo Silva, R. C., de Melo Silva, M. C., \& Costa, C. R. B. (2020). Segurança do trabalho no ambiente hospitalar frente à pandemia da COVID-19. Revista de Atenção à Saúde, 18(65).

Menezes, R. M., Cardoso, V., Hoehr, C. F., Bulle, D., Burgos, M. S., Benitez, L. B., \& Renner, J. D. P. (2016). Avaliação microbiológica da antissepsia préoperatória das mãos de profissionais de enfermagem de um centro cirúrgico. Revista de Epidemiologia e Controle de Infecção, 1(1), $178-191$.

Miranda, F. M. D. A., de Lima Santana, L., Pizzolato, A. C., \& Sarquis, L. M. M. (2020). Condições de trabalho e o impacto na saúde dos Profissionais de enfermagem frente a COVID-19. Cogitare enfermagem, 25.

Nunes, V. R. T., Dias, J. S. R., Nogueira, H. P. P., de Assis, A. C., Brenck, L. F., Andrade. G. L., \& Aguiar Jr, M. C. Cuidados cirúrgicos durante a pandemia mundial do COVID-19: rotinas alternativas para minimizar os riscos. Revista Médica de Minas Gerais, 31 e31701.

Oliveira, A. C. D., Lucas, T. C., \& Iquiapaza, R. A. (2020). O que a pandemia da covid-19 tem nos ensinado sobre adoção de medidas de precaução? Texto \& Contexto-Enfermagem, 29.

Oliveira, C. S., de Oliveira Pinheiro, G., de Freitas, B. C., Figueiredo, B. M., Macedo, W. T. P., \& da Silva, E. D. C. L. (2017). Checklist de cirurgia segura: os desafios da implantação e adesão nas instituições hospitalares brasileiras. Revista Espaço Ciência \& Saúde, 5(2), 72-86. 
Oliveira, E. C. D. S., Silva, F. P. D., Pereira, E. B. F., \& Oliveira, R. C. D. (2020). Ações da comissão de controle de infecção hospitalar frente ao novo coronavírus. Rev. baiana enferm.

Oliveira, T. D. C., Gonçalves, P. A., \& Lima, T. A. D. C. (2020). Adaptação da lista de verificação de cirurgia segura para o contexto da COVID-19. Enferm. foco, $114-120$.

Parreira, S. T., Ribeiro, G., Coelho, J., \& Borges, L. (2020). Cuidados de Enfermagem em Tempos de Pandemia: Uma Realidade Hospitalar. Gazeta Médica.

Parreira, J. G., Campos, T. D., Antunes, P. D. S. L., Perlingeiro, J. A. G., \& Assef, J. C. (2020). Conduta nas urgências e emergências cirúrgicas não traumáticas durante a pandemia COVID-19. Revista do Colégio Brasileiro de Cirurgiões, 47.

Rafael, R. D. M. R., Neto, M., de Carvalho, M. M. B., David, H. M. S. L., Acioli, S., \& de Araujo Faria, M. G. (2020). Epidemiologia, políticas públicas e pandemia de Covid-19: o que esperar no Brasil? Revista enfermagem UERJ, 28, 49570.

Ribeiro, P. A., Oliveira, G. L., Silva, L. S. Souza, E. R., (2020). Saúde e segurança de profissionais de saúde no atendimento a pacientes no contexto da pandemia de Covid-19: revisão de literatura. Revista Brasileira de Saúde Ocupacional 2020; 45:e25.

Rocha, J. P. J., \& Lages, C. A. S. (2016). O Enfermeiro e a prevenção das infecções do sítio cirúrgico. Cadernos UniFOA, 11(30), 117-128.

Santos, C. F., (2020). Reflexões sobre o impacto da pandemia SARS-COV-2 / COVID-19 na saúde mental. Revista Brasileira de Psiquiatria, 42 (3), 329.

Saraiva, E. M. S., Ricarte, É. C., Coelho, J. L. G., de Sousa, D. F., da Silva Feitosa, F. L., Alves, R. S., \& de Santana, W. J. (2020). Impacto da pandemia pelo Covid-19 na provisão de equipamentos de proteção individual. Brazilian Journal of Development, 6(7), 43751-43762.

Siman, A. G., \& Brito, M. J. M. (2016). Mudanças na prática de enfermagem para melhorar a segurança do paciente. Revista Gaúcha de Enfermagem, 37(SPE).

Silva, M. D. S. L., \& Brasileiro, M. E. (2018). Principais Indicadores de Qualidade da Assistência de Enfermagem em Bloco Cirúrgico: Revisão Integrativa da Literatura. Revista Científica Multidisciplinar Núcleo do Conhecimento, 77-98.

Sousa, C. S., \& acuña, A. A., (2020). Treinamento e qualificação dos profissionais de enfermagem do bloco cirúrgico para atendimento de pacientes infectados com coronavírus sars-cov-2 em áreas externas. Revista SOBECC, 25(4): 195- 196.

Souza, M. T. D., Silva, M. D. D., \& Carvalho, R. D. (2010). Revisão integrativa: o que é e como fazer. Einstein (São Paulo), 8(1), 102-106.

Souza, M. A. R. D., Wall, M. L., Thuler, A. C. D. M. C., Lowen, I. M. V., \& Peres, A. M. (2018). O uso do software IRAMUTEQ na análise de dados em pesquisas qualitativas. Revista da Escola de Enfermagem da USP, 52.

Takeiti, M. H., de Oliveira, R. C., \& da Santa Cruz, A. C. (2021). Reestruturando o trabalho no bloco cirúrgico com a pandemia da COVID-19. Revista SOBECC, 26(1).

Trevilato, D. D., Jost, M. T., Araujo, B. R., Martins, F. Z., Magalhães, A. M. M. D., \& Caregnato, R. C. A. (2020). Centro cirúrgico: recomendações para o atendimento de pacientes com suspeita ou portadores de COVID-19. Rev. SOBECC, 187-193. 